\title{
A EVOLUÇÃO DOS MODELOS TEÓRICOS DA ADMINISTRAÇÃO PÚBLICA E OS CAMINHOS PARA O FORTALECIMENTO DA EDUCAÇÃO COMO POLÍTICA PÚBLICA EM DEFESA DOS DIREITOS HUMANOS
}

\author{
Débora de Cássia Baptista Almeida ${ }^{1}$ \\ Ana Beatriz Getelina Sousa ${ }^{2}$
}

Resumo: Esta pesquisa analisará as transformações do Estado dinástico para o Estado burocrático e a evolução dos modelos teóricos da Administração Pública. O objetivo central do ensaio é investigar a atuação do Estado na concretização das políticas públicas voltadas à educação como política pública para a proteção dos direitos humanos. O estudo realizou-se apoiado no método dedutivo, na pesquisa bibliográfica e qualitativa. Ao final, sendo verificado que a evolução dos modelos de Administração Pública é importante ao reconhecimento das lutas pelos direitos humanos, revela-se a importância de fortalecer a educação em tais direitos.

Palavras-chave: Modelos teóricos, Administração pública, Políticas públicas, Educação, Direitos humanos.

\section{THE EVOLUTION OF THEORETICAL MODELS OF PUBLIC ADMINISTRATION AND THE PATHS TO THE EMPOWERMENT OF EDUCATION AS A PUBLIC POLICY IN DEFENSE OF HUMAN RIGHTS}

\begin{abstract}
This research will analyze the transformations from the dynastic State to the bureaucratic State and the evolution of theoretical models of Public Administration. The central objective of the essay is to investigate the role of the State in implementing public policies aimed at education as a public policy for the protection of human rights. The study was based on the deductive method, bibliographical and qualitative research. At the end, being verified that the evolution of the Public Administration models is important for the recognition of the fights for human rights, the importance of strengthening education in such rights is revealed.
\end{abstract}

Keywords: Theoretical models, Public administration, Public policy, Education, Human rights.

\section{INTRODUÇÃO}

\footnotetext{
${ }^{1}$ Mestranda pela Universidade La Salle - Canoas/Rio Grande do Sul; Pós-graduanda pela Uniritter- Porto Alegre em Direito e Processo Civil; Graduada em Ciências Jurídicas e sociais pela Universidade Luterana do Brasil São Jerônimo/Rio Grande do Sul. E-mail: deboracbaptista @ hotmail.com;

${ }^{2}$ Mestranda em Direito pela Universidade La Salle (Canoas/RS). Pós-graduanda em Direito Público pela Faculdade Metropolitana do Estado de São Paulo (FAMEESP). Graduada em Direito pela Universidade Federal do Maranhão (2020). Realizou mobilidade acadêmica internacional na Faculdade de Direito da Universidade de Coimbra no primeiro semestre de 2017 (Programa de Bolsas Ibero-Americanas). E-mail: biagetelina@gmail.com.
} 
A transformação do Estado dinástico para o Estado burocrático buscou constituir-se como uma quebra de paradigma a partir da retirada do poder das mãos dos soberanos para uma legítima administração dos bens de todos. Com isso, o estudo dos modelos teóricos da Administração Pública brasileira se faz necessário, na intenção de investigar se com a supressão do poder das mãos do rei, havendo a separação do que é público e do que é privado, a defesa aos direitos humanos seria fomentada pelos poderes públicos.

Logo, a averiguação da importância da atuação do Estado na implementação e concretização das políticas públicas, no intento de salvaguardar os direitos humanos, revela-se necessária ao presente trabalho, tendo sido escolhido, para uma perquirição mais profunda, o direito à educação.

À vista disso, a educação é um direito que está estabelecido na Constituição Federal de 1988 (CF/1988) em seu quadrante dos direitos sociais, sendo assim considerado um direito fundamental, o que gerou um grande avanço para o Estado Constitucional. No entanto, cabe ressaltar que, antes de ser visto como um direito positivado no texto Constitucional doméstico, importante ressaltar a previsão do direito educacional advinda da Declaração dos Direitos Humanos, a qual foi proclamada em 1948.

Com efeito, emerge o seguinte questionamento: é possível inferir que a evolução dos modelos teóricos da Administração Pública contribui para o fortalecimento da educação como política pública em direitos humanos?

Assim, o objetivo geral da pesquisa é analisar a atuação do Estado na concretização das políticas públicas voltadas à educação como política pública para a proteção dos direitos humanos. Os objetivos específicos, por sua vez, são: a) perquirir as transformações dos modelos teóricos da Administração Pública; b) investigar a contribuição do Estado para a implementação das políticas públicas de educação em direitos humanos; e c) averiguar a relação entre o direito à educação e a concretização dos direitos humanos.

Para tanto, o trabalho está dividido em três partes: primeiramente, analisar-se-á a transformação do Estado dinástico para o Estado burocrático, bem como o estudo dos modelos teóricos da Administração Pública brasileira e os reflexos nos direitos humanos; em um segundo momento, apresentar-se-ão considerações sobre as políticas públicas como responsabilidade de implantação pelos poderes públicos e, por fim, no terceiro tópico, destacar-se-á o direito à educação em defesa dos direitos humanos. 
Por conseguinte, quanto à metodologia, este artigo está baseado no método dedutivo, de modo que serão utilizadas as técnicas da pesquisa bibliográfica e documental nas diversas fases da pesquisa.

\section{A EVOLUÇÃO DOS MODELOS TEÓRICOS DA ADMINISTRAÇÃ̃ PÚBLICA E O REFLEXO NOS DIREITOS HUMANOS}

O campo administrativo é espaço importante para a implementação e concretização de políticas públicas voltadas à defesa dos direitos humanos ${ }^{3}$. Antes, porém, de adentrar na efetivação de políticas públicas como mecanismo a salvaguardar os direitos humanos, faz-se necessário uma análise acerca da formação do campo administrativo, especialmente porque os vestígios do período em que a dominação estava pautada na intenção de manter o poder nas mãos de poucos mostram-se ainda vigentes, o que dificulta a efetividade de proteção dos direitos humanos.

Com efeito, necessário ocupar-se com a transformação do Estado dinástico para o Estado burocrático. Embora Souza (2017) argumente que a conceituação de campo burocrático e Estado não deva ser confundida, Bourdieu (2014) analisa o campo burocrático como parte do campo estatal ${ }^{4}$, tendo este, outros campos, como o campo político, de modo que utiliza a gênese do Estado burocratizado ${ }^{5}$ para desenvolver a passagem dentre esses dois modelos.

Nesse panorama, convém esclarecer que o Estado dinástico se instaurou pela família real, de maneira que se perfaz como uma reprodução através da linhagem, na qual a família, na intenção de manter-se no poder, segue a transmissão hereditária em linhagem agnatícia ${ }^{6}$. Verifica-se, então, que através da reprodução familiar a perpetuação do patrimônio era

\footnotetext{
${ }^{3}$ Os direitos humanos, nas palavras de Bobbio (2004, p. 13), "são aqueles cujo reconhecimento é condição necessária para o aperfeiçoamento da pessoa humana, ou para o desenvolvimento da civilização, [...]."

${ }^{4}$ Souza (2017, p. 34) argumenta que "a lógica do campo burocrático irá tocar o Estado em razão desse campo estar contido no Estado e definir o Estado como burocrático, mas existem outros campos dentro do Estado que lutarão por terem sua lógica também aplicada, como por exemplo, o campo político e o campo econômico que possuem uma estrutura diferente do campo burocrático."

${ }^{5}$ Bourdieu (2005, p. 44) explica que "hay que interrogarse so sobre los factores de la aparición del Estado, sino sobre la lógica del proceso histórico según el cual fue producido, en y por una suerte de cristalización, la emergencia en tanto que sistema de esta realidad histórica sin precedente que es el Estado dinástico y, más extraordinario todavía, el Estado burocrático.

${ }^{6}$ Quanto à linhagem agnatícia, Bourdieu (2014, p. 438) aduz que "isto é, uma transmissão pelos homens, pela primogenitura, pelo morgadio, e pela prioridade dada à transmissão do patrimônio em relação a qualquer outro imperativo."
} 
assegurada. (BOURDIEU, 2014).

A propósito, cabe mencionar a concepção de direitos humanos como uma utopia, segundo a qual Sorondo (1991) ensina que esses direitos são afetados pelas circunstâncias históricas, sendo uma incompleta tomada de consciência das pessoas em frente a situações de injustiça. Assim sendo, cabe a relação da utopia citada por Sorondo (1991) com o Estado dinástico apresentado por Bourdieu (2014), a fim de refletir sobre a garantia dos direitos humanos aos cidadãos no período em que houve a prevalência do comando do soberano.

Destarte, a transição entre os dois modelos mencionados se apresenta quando o Estado deixa de ser deduzido como a "casa" do rei e passa a ser um campo de forças pela dominação legítima dos bens públicos. Assim, nota-se que há a insurgência ao paradigma anterior de que tanto o público quanto o privado eram patrimônios pertencentes à "casa" do rei. (BOURDIEU, 2005).

Dessa feita, necessário destacar os ensinamentos de Rudnicki (2009, p. 169):

\begin{abstract}
Assim, os direitos humanos resultam de radical inversão de perspectiva, na qual não mais vigem direitos dos soberanos e, sim, direitos dos cidadãos, ou seja, abandonase a relação súdito/soberano e alcança-se uma relação entre cidadão/Estado. $\mathrm{O}$ rei já não é mais o Estado, já não mais tudo pode. Aos reis absolutistas foram sendo impostos limites. (RUDNICKI, 2009, p. 169).
\end{abstract}

Logo, percebe-se que o Estado dinástico possui um modo de reprodução baseado na hereditariedade, em que há prevalência da força do sangue para a manutenção da família do rei como chefes da "casa" e, por conseguinte, tendo o Estado como patrimônio particular. No entanto, o Estado burocrático, diferentemente da reprodução sanguínea apresentada naquele modelo, desenvolve-se por uma reprodução vinculada principalmente pelo sistema escolar, bem como com o surgimento do corpo de funcionários. Aqui, a competência e o mérito ${ }^{7}$ restam por minar a legitimidade advinda do nascimento. (BOURDIEU, 2005).

Assim, após a compreensão sobre a transição mencionada, faz-se necessário analisar os três modelos teóricos da Administração Pública brasileira, quais sejam: a Administração patrimonialista, que converge ao modelo dinástico; a Administração burocrática, convergente ao Estado burocrático de Bourdieu; e, ao final, cabe o estudo do modelo mais hodierno que é

\footnotetext{
${ }^{7}$ Segundo Bourdieu (2005, p. 55), "el paso del Estado dinástico al burocrático es inseparable del movimiento por el cual la nueva nobleza, la nobleza de Estado (de toga), expulsa a la antigua nobleza, la nobleza de sangre. Se comprueba de paso que los medios dirigentes han sido los primeros en conocer un proceso que se extendió, mucho más tarde, al conjunto de la sociedad: el paso de un modo de reproducción familiar (que no conoce la división entre lo público y lo privado) y un modo de reproducción burocrático de componente escolar, fundado sobre la intervención de la escuela en el proceso de reproducción."
} 


\section{A EVOLUÇÃO DOS MODELOS TEÓRICOS DA ADMINISTRAÇÃO PÚBLICA E OS CAMINHOS \\ PARA O FORTALECIMENTO DA EDUCAÇÃO COMO POLÍTICA PÚBLICA \\ EM DEFESA DOS DIREITOS HUMANOS}

o gerencial.

À vista disso, o ideal patrimonialista vivenciado no Brasil, como herança histórica oriunda da colonização brasileira por Portugal $^{8}$, em que o patrimonialismo ${ }^{9}$ irrompe em uma ordem estamental, verifica-se uma dominação de entendimentos e de poder pelo rei e seus representantes por delegação, sobrepondo a vontade deste aos governados. (FAORO, 2001).

Importante mencionar, ainda, que se acredita que os direitos humanos chegaram ao Brasil a partir dos ideais europeus de liberdade e igualdade. Ocorre que, ao contrário desses valores, observou-se diversos episódios de opressões e explorações ao longo da história brasileira, de modo a expandir um colonialismo vigorante, em certos aspectos, até hoje. (ESCRIVÃO FILHO; SOUSA JUNIOR, 2016).

Quanto ao ensejo da luta dos direitos humanos, importante citar as palavras de Escrivão Filho e Sousa Júnior (2016, p. 73):

Eis aqui um marco para a análise da história dos direitos humanos no Brasil, qual seja, a noção de que constitui uma história que encontra nas dimensões e consequências da sociedade colonial não um trunfo, mas a sua própria condição emblemática que dá ensejo às lutas por libertação e dignidade, que caracterizam os direitos humanos. (ESCRIVÃO FILHO; SOUSA JÚNIOR, 2016, p. 73).

De acordo com Penna (1988), o anseio pelo privilégio é constatado na estrutura patriarcal e aristocrática da sociedade brasileira. As relações mediante os laços afetivos tendem a exigir o privilégio a seus integrantes, em que a mãe privilegia o filho, o senhor, o seu protegido, o patrão, o cliente, surgindo, assim, uma ordem clientelista e familiar que se mantém pelos benefícios concedidos a seus membros em discriminação aos demais. Nesse sentido, Escrivão Filho e Sousa Junior (2016, p. 98) aduzem que “[...] negando a diversidade, e assim fomentando a discriminação; e recorrendo à violência física e simbólica no espaço público, privado e doméstico como forma de controle social.”.

A partir da segunda metade do século XIX, o capitalismo e a democracia despontaram como presença forte e dominante, de maneira que o Estado baseado na não

\footnotetext{
${ }^{8}$ De acordo com Schwarcz (2019), o fato de o Brasil ter sido colônia de Portugal desencadeou a transferência de parcela do Estado lusitano e da Administração Pública de Portugal e, com isso, houve a chegada do patrimonialismo.

${ }^{9}$ O significado de patrimonialismo para Campante $(2003$, p. 155) é "[...] a substantivação de um termo de origem adjetiva: patrimonial, que qualifica e define um tipo específico de dominação. Sendo a dominação um tipo específico de poder, representado por uma vontade do dominador que faz com que os dominados ajam, em grau socialmente relevante, como se eles próprios fossem portadores de tal vontade, o que importa, para Weber, mais que a obediência real, é o sentido e o grau de sua aceitação como norma válida - tanto pelos dominadores, que afirmam e acreditam ter autoridade para o mando, quanto pelos dominados, que crêem nessa autoridade e interiorizam seu dever de obediência."
} 
diferenciação do patrimônio público e do patrimônio privado do soberano se tornou inconcebível. Nesse contexto, surge a Administração Pública burocrática, a qual objetiva a eliminação do nepotismo e corrupção verificados fortemente no patrimonialismo. (PEREIRA, 1998).

Imperioso destacar que o surgimento da burocracia $^{10}$ tem relação com o aparecimento do capitalismo. Segundo Schneider (2012, p. 35), é possível citar diversos fatores para esse acontecimento, a exemplo da "a economia do tipo monetário, o mercado de mão-de-obra, o aparecimento do estado-nação centralizado, e a divulgação da ética protestante."

No Brasil, o modelo teórico burocrático da Administração Pública teve sua inauguração na época do governo de Getúlio Vargas, sendo que no ano de 1936 foi criado o Departamento Administrativo do Serviço Público (DASP), em que despontou a primeira reforma administrativa do Estado brasileiro. A citada reforma tinha por objetivo combater o modelo patrimonialista até então vigente com suas práticas de arbitrariedade das ações públicas. A corrupção e o nepotismo, que eram constatados nesse modelo, já não condiziam com a nova classe brasileira, qual seja, a classe urbana ${ }^{11}$. (DRUMOND; SILVA; SILVEIRA, 2014).

Conjuntamente a esse período de vigência do modelo burocrático no Brasil, nascia a Declaração Universal dos Direito Humanos que, segundo Bobbio (2004, p. 9) "favoreceu [...] a emergência, embora débil, tênue e obstaculizada, do indivíduo, no interior de um espaço antes reservado exclusivamente aos Estados soberanos."

Acontece que, com o crescimento do Estado no século XX e o incremento da responsabilidade estatal no campo social, a exemplo da atuação nas áreas da educação, saúde e previdência, verificou-se, no modelo de Administração burocrático, uma administração morosa e cara, o que revelou a ineficiência no atendimento aos direitos dos cidadãos. (PEREIRA, 1998).

Com efeito, verifica-se que as transações realizadas pelas instituições governamentais se apresentam como mais morosas na tramitação burocrática, sendo que o

${ }^{10}$ Schneider (2012, p. 35) exemplifica que "a burocracia seria um tipo de poder da mesma categoria que o patriarcalismo, o feudalismo e o carismático. À burocracia ou poder burocrático correspondem, as organizações, as organizações burocráticas, ou simplesmente burocracias.

${ }^{11}$ Conforme Schwarcz (2019), "[...] a burocracia do Estado deixou de ser um prolongamento praticamente exclusivo da classe senhorial agrária tradicional, ou dos comerciantes, já estabelecidos e funcionários portugueses recém-chegados ao Brasil, para passar a incluir certos setores oriundos dos serviços urbanos e profissionais liberais. 


\section{A EVOLUÇÃO DOS MODELOS TEÓRICOS DA ADMINISTRAÇÃO PÚBLICA E OS CAMINHOS \\ PARA O FORTALECIMENTO DA EDUCAÇÃO COMO POLÍTICA PÚBLICA \\ EM DEFESA DOS DIREITOS HUMANOS}

setor público com foco na área de direitos humanos precisa de rápidas soluções desenvolvidas em negociações com entidades públicas e organizações internacionais, no intento de ofertar com qualidade os serviços destinados a garantir os direitos sociais. (OLIVEIRA; ONUKI, 2016).

Dessa forma, com o atraso de procedimentos devido ao excesso de formalismos e de regulações, o modelo burocrático deixa de atender de forma eficaz às necessidades da Administração Pública, de modo que outro modelo, o gerencial, despontou na intenção de fortalecer o atendimento aos interesses sociais, diante da expansão da globalização econômica e de tecnologia. (PEREIRA, 1998).

Nessa esteira, o modelo gerencial originou-se na década de 1990, logo após a promulgação da CF/1988, pautando-se na eficiência da Administração Pública na elaboração e execução das demandas e constituindo-se como um marco originário de proteção aos direitos fundamentais. No entanto, foi através do I Plano Nacional de Direitos Humanos $(\mathrm{PNDH})^{12}$, nascido em 1996, que a temática dos direitos humanos assumiu, efetivamente, relevância enquanto assunto de Estado. (SOUZA, 2017; PEREIRA, 1998; ENGELMANN; MADEIRA, 2015).

De acordo com Schneider (2012), apesar de ser possível verificar que o modelo gerencial rompe com o modelo burocrático, ele não deixa de considerar alguns dos princípios oriundos de tal paradigma. A reforma gerencial se apoiou no modelo burocrático, mantendo, mesmo que com algumas flexibilizações, princípios fundamentais, como a admissão por meio de critérios de mérito, as carreiras, a estruturação do sistema de remuneração, as avaliações de desempenho, entre outros. A principal mudança dos modelos burocrático e gerencial reside no controle que deixa de ser por meio dos processos rígidos e morosos para dar enfoque aos resultados obtidos.

A reforma proposta pelo modelo de Administração Pública gerencial acarreta uma redução da intervenção econômica direta do Estado, bem como na sua disposição de oferta de

\footnotetext{
${ }^{12}$ Sobre os Planos Nacionais de Direitos Humanos, Engelmann e Madeira (2015, p. 628-629) aduzem que "o conceito de direitos humanos assumido pelo primeiro PNDH reconhece o papel e a obrigação do Estado como órgão promotor dos direitos humanos, bem como a universalidade e indivisibilidade de tais direitos. A adoção de um conceito largo de direitos humanos, que engloba direitos civis e políticos, mas, também, econômicos, sociais e culturais - pelo governo brasileiro - reforça perspectivas defendidas por organismos internacionais.[...] enquanto o I PNDH privilegiou os direitos civis e políticos, o II PNDH avança na proteção dos direitos sociais, econômicos e culturais. [...] A trajetória mais marcante na luta contra as violações de direitos humanos nessa nova fase é, sem dúvida, a do ex-ministro Vannuchi, cuja atuação na formulação do III PNDH marcou a história recente da consolidação dos direitos humanos no Brasil.
} 
bens e serviços, por outro lado, tende a acrescer no financiamento de atividades desenvolvidas em benefício aos diretos humanos básicos. (PEREIRA, 1998).

Entretanto, por mais que o modelo burocrático e, posteriormente, o gerencial, tenham surgido em combate daqueles ideais oriundos do modelo patrimonialista, na crença de que tal cultura já não mais seria considerada, o que se percebe é que práticas fisiológicas e clientelista ainda se encontram vivas. (PEREIRA, 1998).

Logo, imperioso mencionar que “[...] persistirá no Brasil um sério déficit republicano ${ }^{13}$ enquanto práticas patrimoniais e clientelistas continuarem a imperar no interior do nosso sistema político e no coração de nossas instituições públicas." (SCHWARCZ, 2019, p. 64). A partir de tal análise, percebe-se o reconhecimento do campo burocrático como local propício de luta dos interesses próprios, deixando de lado, por diversas vezes, o dever de atendimento aos direitos dos cidadãos.

Com isso, percebe-se que ainda há um longo caminho a percorrer para que os direitos humanos sejam concretizados pelo poder público, conforme ensina Rudnicki (2009, p. 179):

A luta pelos direitos humanos junto aos órgãos e pessoas responsáveis pela
realização de justiça ainda depende de longa jornada. A implementação real dos
direitos humanos depende de um novo tipo de Estado, com regras efetivamente
justas e democráticas; depende de uma tomada de consciência por parte das pessoas,
a qual se impõe para a construção de um mundo fraterno. Por isso, os direitos
humanos são uma utopia, um ideal comum para povos e nações, um sistema de
valores justos. (RUDNICKI, 2009, p. 179).

Assim, considerando a importância da atuação do Estado na defesa dos direitos humanos, importante a analisar, no tópico a seguir, a contribuição da implantação de políticas públicas para o fortalecimento de tais direitos.

\section{POLÍTICAS PÚBLICAS E DIREITOS HUMANOS}

Sabe-se que os direitos humanos são dinâmicos e se encontram em constante transformação na medida em que a sociedade evolui e com ela surgem novos anseios e novos objetivos. Tanto é que posteriormente à época em que os privilégios eram derivados da

\footnotetext{
${ }^{13}$ Nas palavras de Schwarcz (2019, p. 64), “'República' significa 'coisa pública' — bem comum —, em oposição ao bem particular: a res privata. Por mais tautológico que possa parecer, não pode haver república sem valores republicanos, e por aqui sempre fez falta o interesse pelo coletivo, a virtude cívica e os princípios próprios ao exercício da vida pública. Nos falta, ainda mais, o exercício dos direitos sociais, qual seja, a participação na riqueza coletiva: o direito, ou melhor, o pleno exercício do direito à saúde, à educação, ao emprego, à moradia, ao transporte e ao lazer."
} 


\section{A EVOLUÇÃO DOS MODELOS TEÓRICOS DA ADMINISTRAÇÃO PÚBLICA E OS CAMINHOS \\ PARA O FORTALECIMENTO DA EDUCAÇÃO COMO POLÍTICA PÚBLICA \\ EM DEFESA DOS DIREITOS HUMANOS}

linhagem sanguínea, consagrou-se um período em que os direitos de liberdade, propriedade e segurança despontaram na sociedade, de modo a evidenciar a importância de assegurar esses direitos aos indivíduos. (SORONDO, 1991).

Por conseguinte, segundo Comparato (2010), a primeira geração de direitos humanos desenvolveu-se através de direitos que almejavam a defesa das liberdades civis e políticas dos cidadãos, em oposição à soberania dos órgãos estatais. Já na segunda geração, observa-se a dinâmica evolutiva dos direitos humanos, pois irrompem os direitos econômicos, sociais e culturais.

Como panorama histórico, verifica-se que o aumento da aplicação de mão de obra nas fábricas e, consequentemente, a piora nas condições de vida dos trabalhadores assalariados, contribuiu para revelar a necessidade de uma ordem capaz de garantir condições dignas de vida, que não eram ofertadas aos cidadãos pelo Estado liberal. (SORONDO, 1991).

Assim, não houve apenas a evolução quanto ao conteúdo dos direitos, mas, também, percebeu-se que uma das grandes distinções entre os direitos de primeira e de segunda geração reside na reivindicação aos órgãos competentes para que os direitos humanos sejam concretizados. Dessa maneira, na segunda geração, vislumbra-se uma imposição prestacional ao poder público, o qual, de acordo com as condições financeiras, irá destinar recursos à satisfação dos já referidos direitos econômicos, sociais e culturais dos indivíduos. (SORONDO, 1991).

Por conseguinte, a terceira geração de direitos humanos originou-se tendo por base os direitos dos $\operatorname{povos}^{14}$, de modo que as nações que são carentes de desenvolvimento conscientizam-se da necessária mudança para que possam dispor dos macanismos que visam a garantir os direitos humanos. (SORONDO, 1991).

Destarte, com a evolução das lutas em defesa dos direitos humanos, principalmente em momento posterior à Declaração dos Direitos Humanos de 1948, insvetiga-se a

\footnotetext{
${ }^{14}$ Sobre a terceira geração dos direitos humanos, Comparato (2010, p. 407) aduz que "a grande novidade desse documento normativo, aprovado na $18^{\mathrm{a}}$ Conferência de Chefes de Estado e Governo, reunida em Nairóbi, no Quênia, em junho de 1981, consistiu em afirmar que os povos são também titulares de direitos humanos, tanto no plano interno como na esfera internacional. [...] A Carta Africana, na esteira da Declaração Universal dos Direitos dos Povos, aprovada numa conferência realizada em Argel em 1976, vai mais além, e afirma os direitos dos povos à existência enquanto tal (art. 20, in initio), à livre disposição de sua riqueza e recursos naturais (art. 21), ao desenvolvimento (art. 22), à paz, e à segurança (art. 23) e também à preservação de um meio ambiente sadio (art. 24). [...] O conceito de povo, no direito internacional, ainda não alcançou uma definição consensual. A dificuldade maior para se chegar a tanto consiste em distinguir, com suficiente nitidez, povo de Estado. $\mathrm{O}$ direito internacional regula, desde há muito, o reconhecimento oficial de Estados ou de governos, mas ignora ainda um processo formal de reconhecimento da identidade de povos."
} 
importância de que os poderes públicos sejam diligentes na elaboração e na concretização de políticas públicas ${ }^{15}$ voltadas ao atendimento dos referidos direitos.

Nesse ínterim, cabe transcrever o que estabelece o Art. $2^{\circ}$, da Resolução 53/144, da Assembleia Geral das Nações Unidas, de 9 de dezembro de 1998, a qual prevê a responsabilidade do Estado na efetivação dos direitos humanos:

\begin{abstract}
Artigo 2. ${ }^{\circ}$ 1. Cada Estado tem a responsabilidade e o dever primordiais de proteger, promover e tornar efectivos todos os direitos humanos e liberdades fundamentais, nomeadamente através da adopção das medidas necessárias à criação das devidas condições nas áreas social, económica, política e outras, bem como das garantias jurídicas que se impõem para assegurar que todas as pessoas sob a sua jurisdição, individualmente e em associação com outras, possam gozar na prática esses direitos e liberdades; 2. Cada Estado deverá adoptar as medidas legislativas, administrativas e outras que se revelem necessárias para assegurar que os direitos e liberdades referidos na presente Declaração são efectivamente garantidos. (ASSEMBLEIA GERAL DAS NAÇÕES UNIDAS, 1998, p. 02).
\end{abstract}

À vista disso, de acordo com Bucci (2001), a análise acerca das políticas públicas apresenta-se como relevante, uma vez que se torna imprescindível a concretização dos direitos humanos, em especial, os direitos sociais. Assim, conforme mencionado, os direitos de primeira geração têm por primordial atenção os direitos de liberadade, as chamadas garantias negativas, em que a fruição dos direitos não serão turbados pelo Estado ou mesmo por outro indivíduo. Enquanto os direitos sociais possuem como principal intenção a exigibilidade de que toda pessoa tenha plenas condições de gozar dos direitos humanos de primeira geração, por isso a importância da previsão dos direitos humanos na Declaração de 1948.

A mobilização de políticas públicas voltadas à denúncia ou a efetivação de direitos humanos ressalta a exigibilidade ${ }^{16}$ deles. Dessa maneira, quando esses direitos são compreendidos enquanto produto das lutas sociais por melhores condições de vida, constatase na exigibilidade um duplo efeito, a saber: primeiro, a legitimação da sociedade para exigir a concretização de seus direitos individuais; e segundo, a imposição de que o Estado

\footnotetext{
${ }^{15}$ Em relação à conceituação de "público" e "políticas", Parsons (2007, p. 37) expõe que "Se puede decir que las 'políticas' se ocupan de aquellas esferas consideradas con o 'públicas', a diferencia de una lista parecida que se podría elaborar con expresiones que implican la idea de 'lo privado'. La idea de las políticas públicas presupone la existencia de una esfera o ámbito de la vida que no es privada o puramente individual, sino colectiva. Lo público comprende aquella dimensión de la actividad humana que se cree que requiere la regulación o intervención gubernamental o social, o por lo menos la adopción de medidas comunes."

${ }^{16}$ Sobre a exigibilidade dos direitos humanos, Escrivão Filho e Sousa Junior (2016, p. 66) salientam que "não possui uma forma rígida ou determinada, senão que se realiza a partir de estratégias de interlocução e controle social das políticas públicas; estratégias de pressão social que podem extrapolar as vias formais e a ordem estabelecida, desde que com vistas à conquista de direitos; e ações voltadas para a produção de sentidos, da cultura de direitos, da formação de lideranças, formação da opinião pública, através de paralisações, mobilizações, etc."
} 


\title{
A EVOLUÇÃO DOS MODELOS TEÓRICOS DA ADMINISTRAÇÃO PÚBLICA E OS CAMINHOS \\ PARA O FORTALECIMENTO DA EDUCAÇÃO COMO POLÍTICA PÚBLICA \\ EM DEFESA DOS DIREITOS HUMANOS
}

mantenha de forma ativa a proteção aos direitos humanos. (ESCRIVÃO FILHO; SOUSA JUNIOR, 2016).

Com efeito, o campo da Administração Pública se perfaz como um espaço oportuno para o desenvolvimento da legitimação social no que tange à exigibilidade pela execução de políticas públicas que assegurem os direitos humanos. (ESCRIVÃO FILHO; SOUSA JUNIOR, 2016).

Nesse panorama, o campo burocrático administrativo se consubstancia em um espaço de implementações de políticas públicas voltadas ao atendimento da sociedade, de modo que, conforme Bourdieu (1996), esse campo $^{17}$ é alicerçado pela ideologia do universal, em que o serviço público é tido como primordial e os interesses pessoais dos agentes públicos são sacrificados pelo interesse público/universal.

As políticas públicas consideradas como campo tornam possível a verificação de lutas, marcadas pela busca da dominação da prática executória das políticas públicas, o que se revela como expectação no alcance de privilégios nos mais diversos campos, a exemplo do econômico, social e cultural. Por conseguinte, diante dos esforços da sociedade dirigidos à proteção dos direitos humanos e da busca pela prestação positiva do Estado na implementação de políticas públicas, faz-se necessário que esses direitos se configurem como poder estruturante e que sejam estruturados. (BOURDIEU, 1989).

Com efeito, importante mencionar os ensinamentos de Bourdieu (1989, p. 09) sobre os sistemas simbólicos como instrumentos estruturados e estruturantes:

\begin{abstract}
Os 'sistemas simbólicos', como instrumentos de conhecimento e de comunicação, só podem exercer um poder estruturante porque são estruturados. O poder Simbólico é um poder de construção da realidade que tende a estabelecer uma ordem gnoseológica: o sentido imediato do mundo (e, em particular, do mundo social) supõe aquilo que Durkheim chama o conformismo lógico, quer dizer, 'uma concepção homogênea do tempo, do espaço, do número, da causa, que torna possível a concordância entre as inteligências. (BOURDIEU, 1989, p. 09).
\end{abstract}

Dessa forma, percebe-se que a estrutura dos direitos humanos só será considerada como uma estrutura estruturante se for reconhecida como estrutura dominante. Por isso, a importância das políticas públicas voltadas à proteção dos direitos humanos, não só como

\footnotetext{
${ }^{17}$ Campo burocrático, nas palavras de Bourdieu (2014, p. 654), é “[...] um campo que está sobrelevado em relação a todos os campos, um campo no qual se decretam intervenções que podem ser econômicas como as subvenções, que podem ser jurídicas como a instauração do regulamento sobre a aposentadoria etc. O campo burocrático, como campo no qual se editam normas referentes aos outros campos, é ele mesmo um campo de luta, em que se encontra o vestígio de todas as lutas anteriores.”
} 
mecanismos capazes de assegurar à sociedade tais direitos, mas, também, como meio de fortalecimento das lutas sociais evolutivas dos direitos humanos. (RUDNICKI, 2009).

Na visão de Pinheiro (2008), o século XX tanto pode ser lembrado pelas guerras, holocausto, genocídio, limpeza étnica, entre tantas outras catástrofes ocorridas, como também pelo fortalecimento da garantia dos direitos humanos. No Brasil, verificou-se um célere avanço em incorporar os direitos protegidos pela Convenção Americana dos Direitos Humanos, de modo que se faz necessário que o poder público dê continuidade à execução de políticas públicas que garantam a proteção dos direitos humanos. (CAMBIAGHI; VANNUCHI, 2013).

Segundo Saule Júnior (2001), um importante avanço na defesa dos direitos humanos foi o reconhecimento internacional do poder local como peça-chave no desenvolvimento de ações voltadas à concretização dos direitos da pessoa. A Conferência das Nações Unidas sobre Assentamentos Humanos - Habitat II teve como resultado importante o reconhecimento do poder local como parte integrante do direito internacional ao lado dos Estados Nacionais e dos cidadãos. Na referida Conferência, o governo brasileiro assumiu o comprometimento de fortalecer o poder local, na intenção de que este atue na implementação dos direitos humanos. Nas palavras de Saule Júnior (2001, p. 18):

O fortalecimento do papel do poder local para enfrentar os problemas urbanos como o desemprego, a degradação ambiental, a exclusão social, tornou-se um dos novos paradigmas no processo de globalização para a promoção do desenvolvimento sustentável nas cidades. (SAULE JÚNIOR, 2001, p. 18).

Nesse contexto, imperioso mencionar que, no Brasil, os Municípios passaram a ter reconhecimento como sujeitos federativos assim como a União, os Estados e o Distrito Federal, a partir da promulgação da CF/1988. Desse modo, os entes municipais passaram a ter uma maior capacidade política e econômica, o que reflete em um avanço na efetivação das políticas públicas a seu encargo, tal responsabilidade se perfaz de forma solidária entre Municípios, Estados e União, nos termos constitucionais. (SAULE JÚNIOR, 2001).

Por conseguinte, verifica-se que a atuação do Estado, no tocante à efetivação de políticas públicas, mostra-se de suma importância na luta em defesa dos direitos humanos, de modo que, no tópico a seguir, faz-se necessário averiguar o direito à educação como umas das políticas capazes de contribuir para o fortalecimento dos direitos.

\section{A EDUCAÇÃO EM DIREITOS HUMANOS}


Para analisar o tema da educação em direitos humanos, importante abordar a formação educacional dos indivíduos e o papel da escola. Para tanto, convém mencionar que a família é o primeiro espaço em que a criança começa a formar sua educação e onde inicia o seu processo de desenvolvimento, pensamento e escolha. No entanto, é na educação escolar que ela inicia seu gosto pela vida coletiva ${ }^{18}$, pois a escola é vista como uma sociedade, de modo que a partir dela outros grupos se desenvolvem. (DURKHEIM, 2008).

À vista disso, embora a análise do campo escolar renda uma gama de discussões, não é o objetivo do presente estudo, pois cabe aqui investigar a importância do direito à educação como um dos mecanismos de defesa dos direitos humanos, especialmente em momentos de crise sanitária e econômica que tanto o Brasil como o mundo de uma forma geral têm enfrentado.

Nesse período de crise, que tende a afetar as instituições democráticas e ressaltar as desigualdades sociais, verifica-se a importância em educar a população em direitos humanos, com vistas a conscientizar acerca da necessidade de promover as garantias de saúde, educação, de segurança, dentre outros direitos básicos. A preocupação sobre esse tema não é recente, sendo imperioso remontar à Declaração Universal dos Direitos Humanos proclamada pela Organização das Nações Unidas, de 1948, a qual ostenta em seu preâmbulo a importância de que os direitos elencados sejam respeitados por todos os povos e nações. Desse modo, estabelece que os indivíduos e os órgãos sociais devem se empenhar para assegurar os direitos por meio da educação, que é uma garantia prevista no Art. 26 da Declaração $^{19}$. (ORGANIZAÇÃO DAS NAÇÕES UNIDAS, 1948).

Percebe-se que a referida Declaração, além de expressamente prever o direito à

\footnotetext{
${ }^{18}$ Quanto ao gosto pela vida coletiva, Durkheim $(2008$, p. 233) expõe que "todo o problema consiste em aproveitar essa associação na qual as crianças se encontram obrigatoriamente, para fazer com que tomem gosto por uma vida coletiva mais ampla e mais impessoal do que aquela à qual estava habituada. Ora, essa não é uma dificuldade intrasponível; na realidade, nada é mais agradável do que a vida coletiva, mesmo quando não se está habituado a ela desde pequeno. Um de seus efeitos é aumentar a vitalidade de cada indivíduo. Temos mais autoconfiança, nos sentimos mais fortes, quando sentimos que não estamos sozinhos."

19 "Artigo 26 da Declaração Unversal dos Direitos Humanos:

1. Todo ser humano tem direito à instrução. A instrução será gratuita, pelo menos nos graus elementares e fundamentais. A instrução elementar será obrigatória. A instrução técnico-profissional será acessível a todos, bem como a instrução superior, esta baseada no mérito. 2. A instrução será orientada no sentido do pleno desenvolvimento da personaidade humana e do fortalecimento do respeito pelos direitos do ser humano e pelas liberdades fundamentais. A instrução promoverá a compreensão, a tolerância e a amizade entre todas as nações e grupos raciais ou religiosos e coadjuvará as atividades das Nações Unidas em prol da manutenção da paz. 3. Os pais têm prioridade de direito na escolha do gênero de instrução que será ministrada a seus filhos." (ORGANIZAÇÃO DAS NAÇÕES UNIDAS, 1948).
} 
educação como sendo uma garantia a ser resguardada, reforça, ainda, a relevância educacional na vida em sociedade, uma vez que exprime o respeito aos direitos humanos, de maneira que os povos devem esforçar-se para assegurá-los a partir do ensino e da educação.

Ademais, no âmbito nacional, imperioso mencionar que a partir da CF/1988 a educação ganhou maior visibilidade, sendo estabelecido como um direito público subjetivo ${ }^{20}$. Segundo Silva (2013, p. 317), “[...] é direito plenamente eficaz e de aplicabilidade imediata, isto é, direito exigível judicialmente, se não for prestado espontaneamente."

Tal é sua relevância que a educação é direito que se encontra previsto no Art. $6^{\circ}$ da CF/1988, que estabelece diversos direitos de natureza social, a exemplo da educação, saúde e previdência social. Dessa forma, verifica-se que a educação é instrumento indispensável à inclusão social e ao desenvolvimento da sociedade. (DELEVATTI, 2006).

Ocorre que, embora a educação brasileira tenha evoluído positivamente enquanto direito fundamental, é a partir dos Planos Nacionais de Direitos Humanos que se tem um reconhecimento da obrigação do Estado como responsável pela efetividade dos direitos humanos, como também, a universalidade e indivisibilidade de tais direitos. Todavia, com o I PNDH se privilegiou os direitos civis e políticos, enquanto o II PNDH expandiu a proteção dos direitos sociais, econômicos e culturais, estando assim, o direito à educação incluído a partir deste Plano. (ENGELMANN; MADEIRA, 2015).

Além disso, merece destaque o Plano Nacional de Educação em Direitos Humanos (PNEDH) cujos pressupostos estão intrinsecamente relacionados ao Estado Democrático de Direito e aos valores da cidadania, da democracia e da justiça social. (BRASIL, 2018).

Com efeito, o PNEDH, que apresenta cinco eixos de atuação que perpassam desde a Educação Básica à Educação e Mídia, almeja fomentar a proteção aos direitos humanos a partir de ações conjuntas entre a sociedade civil e as instituições públicas que busquem incrementar as políticas educacionais. (BRASIL, 2018).

Com a finalidade de fortalecer a cultura da educação em direitos humanos, necessário mencionar a Resolução $\mathrm{n}^{\mathrm{o}} 1$, de 30 de maio de 2012, que dentre os diversos dispositivos, revela os princípios norteadores, no Art. $3^{\text {o21 }}$, e a importância da integração dos

\footnotetext{
20 “Art. 208. O dever do Estado com a educação será efetivado mediante a garantia de: $\S 1^{\circ} \mathrm{O}$ acesso ao ensino obrigatório e gratuito é direito público subjetivo." (BRASIL, 1988).

21 "Art. $3^{\circ} \mathrm{A}$ Educação em Direitos Humanos, com a finalidade de promover a educação para a mudança e a transformação social, fundamenta-se nos seguintes princípios:

I - dignidade humana;

II - igualdade de direitos;
} 


\section{A EVOLUÇÃO DOS MODELOS TEÓRICOS DA ADMINISTRAÇÃO PÚBLICA E OS CAMINHOS \\ PARA O FORTALECIMENTO DA EDUCAÇÃO COMO POLÍTICA PÚBLICA \\ EM DEFESA DOS DIREITOS HUMANOS}

mais variados programas e projetos para concretizar essa política pública, nos termos do Art. $6^{\text {o22 }}$

Logo, o PNEDH representa um marco importante para o Brasil, pois revela a preocupação acerca da educação como política pública de promoção e defesa dos direitos humanos, os quais englobam não apenas os direitos civis e políticos previsto na Carta Magna, mas também, os direitos sociais, econômicos, culturais, e demais direitos compreendidos nos Arts. $6^{\circ}$ e $7^{\circ}$ da CF/1988 e nas seções especiais do texto constitucional. (CICONELLO, 2016).

Nesse contexto, diante da proteção aos direitos humanos, cabe destacar os três princípios que foram expressos na Conferência Mundial de Viena de 1993, quais sejam: a) universalidade: verifica-se que a proteção outorgada aos direitos humanos vale para a totalidade de pessoas, assim, não importa condições sociais, pessoais ou mesmo identitárias, pois nenhuma condição justifica o desrespeito aos direitos humanos; b) indivisibilidade: cada direito humano, como o direito a saúde, a educação etc., possuem características específicas que devem ser atendidas de forma plena. Os direitos humanos não podem ser fracionados ou reduzidos, não bastando para sua concretização que se garanta o acesso a determinado direito, sendo necessário garantir um exercício de direito de qualidade; c) interdependência: constatase que não há hierarquia entre os direitos humanos, todas as dimensões dos direitos estão conectadas entre si. Dessa forma, para que um direito seja efetivamente concretizado, outros direitos necessitam ser conjuntamente garantidos. (CICONELLO, 2016).

No que tange à característica da universalidade, segundo compreensão de Ferrajoli (1999), ela se destina a classe de sujeitos, os quais possuem sua titularidade reconhecida normativamente, partindo, assim, de uma definição formal. Logo, estabelece-se, com base no cruzamento dos critérios de cidadania e de capacidade de fato, quatro classes de direitos: 1) direitos humanos: são os direitos destinados a todas as pessoas, incluindo aqui o direito à educação, bem como os direitos de liberdade, saúde, garantias penais e processuais etc.; 2)

III - reconhecimento e valorização das diferenças e das diversidades;

IV - laicidade do Estado;

$\mathrm{V}$ - democracia na educação;

VI - transversalidade, vivência e globalidade; e

VII - sustentabilidade socioambiental." (BRASIL, 2012).

22 “Art. $6^{\circ} \mathrm{A}$ Educação em Direitos Humanos, de modo transversal, deverá ser considerada na construção dos Projetos Político-Pedagógicos (PPP); dos Regimentos Escolares; dos Planos de Desenvolvimento Institucionais (PDI); dos Programas Pedagógicos de Curso (PPC) das Instituições de Educação Superior; dos materiais didáticos e pedagógicos; do modelo de ensino, pesquisa e extensão; de gestão, bem como dos diferentes processos de avaliação.” (BRASIL, 2012). 
direitos públicos: são reconhecidos somente aos cidadãos, sendo direitos substanciais; 3) direitos civis: são os direitos atribuídos a todas as pessoas que possuam capacidade de fato; 4) direitos políticos: direitos instrumentais reservados aos cidadãos com capacidade de fato. (FERRAJOLI, 1999).

Outrossim, consoante Ciconello (2016), a análise de que os direitos humanos possuem características específicas gerou uma série de recomendações produzidas pelos Comitês de Tratados das Nações Unidas (ONU), tratando sobre a delimitação e alcance dos direitos. No que diz respeito à educação, o Comentário Geral no 13 detalha seus atributos sob a luz do direito internacional.

Sendo assim, observa-se que o direito à educação é composto por quatro elementos essenciais: a) disponibilidade: por tal elemento, a educação gratuita deve estar ao alcance de todos, sendo que as normas internacionais de direitos humanos obrigam o Estado ser o investidor final a garantia de instrução; b) acessibilidade: é o acesso à educação sem haver discriminação, onde se possibilite uma acessibilidade material, em que haja efetiva frequência escolar e, independente da condição econômica, o acesso a instrução é assegurado; c) aceitabilidade: garante uma qualidade padronizada da educação, devendo o Estado adaptar-se aos critérios mínimos formulados; d) adaptabilidade: segundo o último elemento, a educação deve ser proposta segundo a realidade das pessoas as quais se destina, considerando a cultural, religião e demais diferenças. (CICONELLO, 2016).

Dessa maneira, vislumbra-se na concretização das políticas públicas educacionais a capacidade de proporcionar mudanças no quadro de patrimonialismo e clientelismo que, conforme já exposto no estudo, ainda revela resquícios na sociedade e macula proteção integral dos direitos humanos, vez que ainda presentes as violações às garantias básicas.

\section{CONSIDERAÇÕES FINAIS}

O presente trabalho buscou, em um primeiro momento, averiguar a mudança de paradigma entre o modelo de Estado que concentrava na pessoa do soberano todos os poderes, resultando a gerência tanto dos bens privados quanto dos bens públicos em domínio do rei, para um Estado em que se constata a separação dos âmbitos privado e público.

No entanto, verificou-se que mesmo com a evolução do modelo patrimonialista para um modelo gerencial, ainda hoje percebem-se fortes traços daquela época. Tal situação reflete 
diretamente na dificuldade de fortalecimento da proteção dos direitos humanos.

Assim, no segundo momento do trabalho, realizou-se uma análise acerca das gerações dos direitos humanos e como isso desencadeou na necessidade de atuação dos poderes públicos voltada à defesa desses direitos, principalmente na segunda geração dos direitos, em que se vislumbrou a relevância da proteção dos direitos econômicos, socais e culturais diante das precárias condições de vida com o avanço do setor fabril. Tal fenômeno reforçou a exigência prestacional dos órgãos públicos no atendimento dos direitos da sociedade.

Ademais, verificou-se o reconhecimento do poder local, pois o município adquiriu maior autonomia de gestão, inclusive financeira, a partir da CF/88. Isso foi de grande relevância para a defesa dos direitos humanos, pois ao ente municipal coube a responsabilidade de implementação e concretização dos direitos mediante a criação das políticas públicas.

À vista disso, foi analisado no último tópico o direito à educação como uma política pública importante em defesa dos direitos humanos. Observou-se que esse direito contribui, de certa forma, para o duplo fortalecimento dos direitos humanos, pois, de um lado permite que as pessoas, de forma gratuita e igualitária, tenham acesso à instrução de qualidade e, de outro, permite que, através do ensino, os ideias das Declarações de Direitos sejam difundidos entre as nações e os povos.

Portanto, conclui-se que a evolução dos modelos de Administração Pública revelouse importante para o reconhecimento das lutas pelos direitos humanos, o que propiciou avanços no tocante à aplicação da educação como política pública destinada ao fortalecimento dos direitos humanos. Apesar de importantes avanços, como a elaboração do PNEDH, que contribui para a promoção da cultura dos direitos humanos, ainda há muito a ser feito. Variados são os desafios, mas, certamente, a educação se revela como o caminho a ser seguido.

\section{REFERÊNCIAS}

BOBBIO, Norberto. A era dos direitos. Tradução de Carlos Nelson Coutinho. Rio de Janeiro: Elsevier, 2004.

BOURDIEU, Pierre. El Misterio del Ministerio: De las voluntades particulares a la "voluntad general" (Trad. Joaquín Rodríguez). In: WACQUAND, Loïc (coord.). El Misterio del 
Ministerio: Pierre Bordieu y la política democrática. 9 ed. Barcelona: Gedisa, 2005.

BOURDIEU, Pierre. O poder simbólico. Tradução de Fernando Tomaz. Rio de Janeiro: Bertrand Brasil, 1989.

BOURDIEU, Pierre. Razões práticas: sobre a teoria da ação. $9^{a}$ ed. São Paulo: Editora Papirus, 1996.

BOURDIEU, Pierre. Sobre o Estado. Cursos no Collège de France (1989-92). Tradução Rosa Freire d'Aguiar. São Paulo: Companhia das Letras, 2014.

BRASIL. Constituição (1988). Constituição da República Federativa do Brasil de 1988. Disponível em: http://www.planalto.gov.br/ccivil_03/constituicao/constituicao.htm. Acesso em: 15 ago. 2021.

BRASIL. Comitê Nacional de Educação em Direitos Humanos. Plano Nacional de Educação em Direitos Humanos. Brasília: Ministério dos Direitos Humanos, 2018. Disponível em: https://www.gov.br/mdh/pt-br/navegue-por-temas/educacao-em-direitoshumanos/DIAGRMAOPNEDH.pdf. Acesso em: 13 set. 2021.

BRASIL. Resolução no 1, de 30 de maio de 2012. Disponível em: http://portal.mec.gov.br/dmdocuments/rcp001_12.pdf. Acesso em: 13 set. 2021.

BUCCI, Maria Paula Dallari. Buscando um conceito de políticas públicas para a concretização dos direitos humanos. In: BUCCI, Maria Paula Dallari et alli. Direitos Humanos e políticas públicas. São Paulo: Pólis, 2001. p. 05-16.

CAMBIAGHI, Cristina Timponi; VANNUCHI, Paulo. Sistema Interamericano de Direitos Humanos (SIDH): reformar para fortalecer. Lua Nova: Revista de Cultura e Política [online]. 2013, n. 90. p. 133-163. Disponível em: https://doi.org/10.1590/S010264452013000300006. Acesso em 15 jul. 2021.

CAMPANTE, Rubens Goyatá. Patrimonialismo em Faoro e Weber. DADOS - Revista de Ciências Sociais. Rio de Janeiro, v. 46, n. ${ }^{\circ}$ 1, 2003, p. 153-93.

CICONELLO, Alexandre. Políticas públicas de direitos humanos. In: ALVES, Pedro Assumpção; DELGADO, Ana Luiza Menezes; GATTO, Carmem Isabel; REIS, Maria Stela (org.). Gestão de políticas públicas de direitos humanos - coletânea. Brasília: ENAP, 2016. p. 161-187.

COMPARATO, Fábio Konder. A afirmação histórica dos direitos humanos. $7^{\mathrm{a}}$ ed. São Paulo: Saraiva, 2010.

DELEVATTI, Alex Faturi. A educação básica como direito fundamental na constituição brasileira. 2006. Dissertação (Mestrado em Ciência Jurídica) -Universidade do Vale do Itajaí-UNIVALI, Itajaí, 2006.

DURKHEIM, Émile David. A educação moral. Rio de Janeiro: Vozes, 2008. 
DRUMOND, Alexandre Matos; SILVEIRA, Suely de Fátima Ramos; SILVA, Edson Arlindo. Predominância ou coexistência? Modelos de administração pública brasileira na Política Nacional de Habitação. Revista de Administração Pública, v. 48, n. 1, p. 3 a 26, 3 fev. 2014.

ENGELMANN, Fabiano; MADEIRA, Lígia Mori. Causa e as políticas de direitos humanos no brasil. Caderno CRH [online]. 2015, v. 28, n. 75, p. 623-637. Disponível em: https://doi.org/10.1590/S0103-49792015000300011. Acesso em: 15 jul. 2021.

ESCRIVÃO FILHO, Antônio; SOUSA JUNIOR, José Geraldo de. Para um debate teóricoconceitual e político sobre os direitos humanos. In: ALVES, Pedro Assumpção; DELGADO, Ana Luiza Menezes; GATTO, Carmem Isabel; REIS, Maria Stela (org.). Gestão de políticas públicas de direitos humanos - coletânea. Brasília: ENAP, 2016. p. 45-117.

FAORO, Raymundo. Os donos do poder: formação do patronato político brasileiro. $3^{\mathrm{a}} \mathrm{ed}$. São Paulo: Globo, 2001.

FERRAJOLI, Luigi. Derechos y garantías: La ley del más débil. Madrid, Trotta, 1999.

FREIRE, Paulo. Educação como prática da liberdade. Rio de Janeiro: Paz e Terra, 1967.

OLIVEIRA, Amâncio Jorge de; ONUKI, Janina. Negociações efetivas para a construção de consensos empolíticas de direitos humanos. In: ALVES, Pedro Assumpção; DELGADO, Ana Luiza Menezes; GATTO, Carmem Isabel; REIS, Maria Stela (org.). Gestão de políticas públicas de direitos humanos - coletânea. Brasília: ENAP, 2016. p. 303-323.

ORGANIZAÇÃO DAS NAÇÕES UNIDAS. Declaração Universal dos Direitos Humanos, 1948. Disponível em: https://www.unicef.org/brazil/declaracao-universal-dos-direitoshumanos. Acesso em: 02 ago. 2021.

PARSONS, Wayne. Políticas públicas: una introducción a la teoría y la práctica del análisis de políticas públicas. Traducción de Atena Acevedo. México: Flacso, 2007.

PENNA, José Osvaldo de Meira. O dinossauro: uma pesquisa sobre o Estado, o patrimonialismo selvagem e a nova classe de intelectuais e burocratas. São Paulo: T. A. Queiroz, 1988.

PEREIRA, Luiz Carlos Bresser. Economia brasileira: uma introdução crítica. $3^{\mathrm{a}}$ ed. São Paulo: Editora 34, 1998.

PINHEIRO, Paulo Sérgio. Os sessenta anos da Declaração Universal: atravessando um mar de contradições. Sur. Revista Internacional de Direitos Humanos [online]. 2008, v. 5, n. 9 p. 76-87. Disponível em: https://doi.org/10.1590/S1806-64452008000200005. Acesso em: 15 ago. 2021. 
PORTUGAL. Ministério Público. Departamento Cooperação Judiciária e Relações Internacionais. Resolução 53/144. Assembleia Geral das Nações Unidas, de 9 de dezembro de 1998. Disponível em: http://www.gddc.pt/direitos-humanos/textos-internacionaisdh/tidhuniversais/o-defensores-dh.html. Acesso em: 16 jul. 2021.

RUDNICKI, Dani. O discurso (ideológico) dos juristas sobre os direitos humanos. In: SILVEIRA, Helder Gordim da; ABREU, Aronne de; MANSAN, Jaime Valim (org.). História e ideologia: perspectivas e debates. Passo Fundo: UPF, 2009. p. 168-179.

SAULE JÚNIOR, Nelson. Políticas públicas locais: município e direitos humanos. In: BUCCI, Maria Paula Dallari et alli. Direitos humanos e políticas públicas. São Paulo: Pólis, 2001. p. 17-31.

SCHNEIDER, Claudio Samuel Santos. A transição para o modelo gerencial na Administração Pública Federal Brasileira. 2012. Artigo (Especialização em Gestão Pública UAB) - Universidade Federal do Rio Grande do Sul, Porto Alegre, 2012.

SCHWARCZ, Lilia Moritz. Sobre o autoritarismo brasileiro. São Paulo: Companhia das Letras, 2019.

SORONDO, Fernando. Os direitos humanos através da história. Porto Alegre: Movimento de Justiça e Direitos Humanos, 1991.

SOUZA, Sâmela Cristina de. Formação e transformação do espaço do direito administrativo brasileiro a partir da teoria de Pierre Bourdieu. 2017. 204 f. Dissertação (Mestrado em Direitos e Garantias Fundamentais) - Programa de Pós-Graduação em Direitos e Garantias Fundamentais, Faculdade de Direito de Vitória, Vitória, 2017. 